\title{
Experimental Study of Iraqi Light Naphtha Isomerization over Ni-Pt/H-Mordenite
}

\author{
Halah M. Hussain and Abdulhaleem A.K. Mohammed
}

Alfaraby University College / Baghdad-Iraq

\begin{abstract}
Hydroisomerization of Iraqi light naphtha was studied on prepared Ni-Pt/H-mordenite catalyst at a temperature range of 220$300^{\circ} \mathrm{C}$, hydrogen to hydrocarbon molar ratio of 3.7 , liquid hourly space velocity (LHSV) $1 \mathrm{hr}^{-1}$ and at atmospheric pressure.

The result shows that the hydrisomerization of light naphtha increases with the increase in reaction temperature at constant LHSV. However, above $270{ }^{\circ} \mathrm{C}$ the isomers formation decreases and the reaction is shifted towards the hydrocracking reaction, a higher octane number of naphtha was formed at $270{ }^{\circ} \mathrm{C}$.
\end{abstract}

Keywords: Iraqi light naphtha isomerization, Nickel-Platinum over H-mordenite.

Received on 09/02/2019, Accepted on 03/04/2019, published on 30/12/2019

https://doi.org/10.31699/IJCPE.2019.4.10

\section{1- Introduction}

The utilization of an upgraded low-value refinery stream to the gasoline pool might present a solution to the problem, as it can considerably lower the cost of gasoline production, while loses only some of its original quality, but still remains environmentally friendly. The use of bifunctional zeolite catalysts specifically designed to enhance the octane number of light nuphtha through the hydroisomerization process has already been marketed.[1].

However, this application has not yet been commercially extended to include the treatment of heavy naphtha, which usually contains normal alkanes from the Heptane range to Decane [2].

Isomerization, cracking and alkylation are acid-induced reactions. The catalyzad hydrocarbon reactions are of great importance nowadays and it is not surprising that many studies have been devoted to this subject. However, important questions remain regarding the mechanism and effect of catalytic pore structure on the activity and selectivity to answer. [3].

Isomerization of n-paraffin to branched paraffin is important in petroleum refining industry for improving motor fuels properties such as high gasoline octane number [4], diesel fuel with high cetane number, low pour point and high viscosity index. To accomplish high isomerization selectivity; balance between the active component (metal) and acid functions is needed [5]

More studies about isomerization to produce high quality gasoline such as Vaudagna, [6] indicated that loading of $\mathrm{Pt}$ on $\mathrm{WO}_{3} / \mathrm{ZrO}_{2}$ have positive effect on the rate and selectivity of alkanes isomerisation in the presence of hydrogen.
The Pt metal was impregnated into the $\mathrm{WO}_{3} / \mathrm{ZrO}_{2}$, so that the catalysts contain $0.4 \mathrm{wt}$. \% of $\mathrm{Pt}$ and the $\mathrm{Pt} /$ $\mathrm{WO}_{3} / \mathrm{ZrO}_{2}$ calcined to a temperature of $830{ }^{\circ} \mathrm{C}$ (at $20 \mathrm{C}$ $\mathrm{min}^{-1}$ ) for 3 hours. The specific surface area was found to increase to more than $350 \mathrm{~m}^{2} / \mathrm{g}$.

Al-Hassany M. [7] studied that Light naphtha treatment achieved over $0.3 \mathrm{wt} \% \mathrm{Pt}$ loaded-alumina, HY-zeolite and $\mathrm{Zr} / \mathrm{W} / \mathrm{HY}$-zeolite catalysts at temperature range of 240$370{ }^{\circ} \mathrm{C}$, hydrogen to hydrocarbon mole ratio of 1-4 with liquid hourly space velocity (LHSV) $0.75-3 \mathrm{hr}^{-1}$, and at atmospheric pressure. Results showed that $\mathrm{Pt} / \mathrm{Zr} / \mathrm{W} / \mathrm{HY}$ is the best catalyst for producing isoparffines due to its higher acidity compared with $\mathrm{Pt} / \mathrm{HY}$. The $\mathrm{Pt} / \mathrm{Zr} / \mathrm{W} / \mathrm{HY}$ catalyst showed lower activity for aromatization of naphtha to cyclopareffins and benzene selectivity than $\mathrm{Pt} / \mathrm{HY}$.

A smaller pore volume leads to lower aromatization activity and higher isomerization and cracking activity. The maximum isoparaffins extent was achieved and reached $78 \%$ at $300{ }^{\circ} \mathrm{C}$ and LHSV of $0.75 \mathrm{hr}^{-1}$ on $\mathrm{Pt} / \mathrm{Zr} / \mathrm{HY}$ and aromatics extent was reached $10 \%$ at 370 ${ }^{\circ} \mathrm{C}$ and LHSV of $0.75 \mathrm{hr}^{-1}$ on $\mathrm{Pt} / \mathrm{HY}$.

Al-Saraj M A A. et al. [8] studied light naphtha isomerization over $0.3 \mathrm{wt}$. \% Pt / HMOR was the catalyst. The operating condition was performed for all temperature experiments from 200 to $350^{\circ} \mathrm{C}$, pressure range from 3 to 15 bar, LHSV - range from $0.5-2.5 \mathrm{hr}^{-1}$, and from hydrogen to naphtha - a ratio of 300 . The results show that the isomerization of the Iraqi light naphtha increases with increasing reaction temperature and decreases with an increase in LHSV. High research octane number (93) was formed at $240^{\circ} \mathrm{C}$. 
In this work the catalytic activity of the promoted prepared catalyst (Pt-Ni/H-mordenite) using light naphtha isomerization was studied at different operating conditions and the chemical composition of produced gasoline using PONA analysis was determined.

\section{2- Experimental Work}

\subsection{Materials}

a. Feedstock

Iraqi light naphtha supplied from Al-Dora Refinery was used as a feedstock in hydroisomerization experiments. The physical properties and PONA analysis of Iraqi light naphtha are listed in Table $\mathbf{1 .}$

Table 1. Physical Properties and PONA analysis of Iraqi light naphtha

\begin{tabular}{ll}
\hline Physical proprties & value \\
\hline Specific gravity at $60^{0} / 60^{0} \mathrm{~F}$ & 0.6631 \\
API gravity & 80.6 \\
Kinematic viscosity at $25^{0} \mathrm{C}, \mathrm{m}^{2} / \mathrm{s}$ & $7.2^{*} 10^{-7}$ \\
Research Octane number & 60 \\
Sulfur content ppm & 1.5 \\
Chemical Composition & $\mathrm{Wt} . \%$ \\
n-Paraffin & 42.9 \\
i-Paraffin & 42.1 \\
Olefin & 0.3 \\
Naphthene & 9.1 \\
Aromatic & 5 \\
\hline
\end{tabular}

\section{b. Chemicals}

The chemicals used for experimental work are tabulated in Table 2.

Table 2. The chemicals used for experimental work

\begin{tabular}{lll}
\hline Chemical & Source(company) & Purity \\
\hline Sodium Hydroxide & Alpha Chemika & $99 \%$ \\
Sulfuric Acid & Sigma Aldrich & $98 \%$ \\
Sodium aluminate & Sigma Aldrich & $50-56 \%$ \\
Ammonium & BDH Limited Pool, & $99 \%$ \\
Chloride & England & \\
Nickel nitrate & Himedia, India & $97 \%$ \\
Cloro platinic acid & Sigma Aldrich & $40 \%$ \\
Hydrogen gas & Al-Dura Power station & $99 \%$ \\
Nitrogen gas & Al-Khalej Plant & $99 \%$ \\
\hline
\end{tabular}

\subsection{Synthesis of Na-mordenite (Na-MOR)}

Na-MOR was synthesized from nano-silica. 38. $90 \mathrm{~g}$ of $\mathrm{NaOH}$ was dissolved in $249.3 \mathrm{ml}$ of water and then divided into two equal portions. In one portion, $5.56 \mathrm{~g}$ of nano-silica was completely dissolved. To the other portion, $10.19 \mathrm{~g}$ of $\mathrm{NaAlO}_{2}$ was added to prepare a clear aluminate solution. Then the silicate solution was slowly poured into the aluminate solution with vigorous stirring, and a homogenous gel resulted.
The resultant gel was stored in a water bath at room temperature ( $\mathrm{T}=25 \pm 2{ }^{\circ} \mathrm{C}$ ), in a sealed poly tetra fluoro ethylene (PTFE) bottle under stirrer at $250 \mathrm{rpm}$ for 3 days at $\mathrm{pH}$ 14. The solid product was separated by filtration (Whatman No. 41 filter paper) using a Buckner funnel with the aid of a vacuum pump, then washed more times by distilled water until the $\mathrm{pH}$ value dropped to 8.69 . The product was left at room temperature overnight, dried at $110^{\circ} \mathrm{C}$ for $2 \mathrm{hr}$ and calcined at $400{ }^{\circ} \mathrm{C}$ for $2 \mathrm{hr}$. [9].

\subsection{Synthesis of H-mordenite (H-MOR)}

The hydrogen form of zeolite H-MOR was obtained from Na-MOR exchange with a solution of $4 \mathrm{~N} \mathrm{NH}_{4} \mathrm{Cl}$. Zeolite Na-MOR was slurred in an ammonium chloride solutions with mixing at $70^{\circ} \mathrm{C}$ for $2 \mathrm{hr}$ and then left at room temperature overnight for ion exchange completion.

After that the exchanged zeolite was filtered off, washed with distilled water. The product was left at room temperature overnight, dried at $110{ }^{0} \mathrm{C}$ for $2 \mathrm{hr}$ and calcined at $400{ }^{\circ} \mathrm{C}$ for $2 \mathrm{hr}$. [10]

\subsection{Preparation of Ni-Pt/H-MOR by impregnation method}

100g of H-MOR-zeolite as a powder was mixed with 10 wt. $\%$ bentonite clay as binder. The resulting mixture was mixed with water to form a paste. Extrudates with 3-7 $\mathrm{mm}$ were formulated and dried over night at $110^{\circ} \mathrm{C}$ and then calcined at $400{ }^{\circ} \mathrm{C}$ for $2 \mathrm{hr}$.

To prepare $0.15 \mathrm{wt} \%$ of $\mathrm{Pt}$ on $50 \mathrm{~g}$ of $\mathrm{H}-\mathrm{MOR}$ pellets the carrier catalyst $\mathrm{H}-\mathrm{MOR}$ was dried at $110^{\circ} \mathrm{C}$ with air for two hours and placed in impregnation under vacuum, then the solution of chloroplatinic acid $\left(0.205 \mathrm{~g} \mathrm{H}_{2} \mathrm{PtCl}_{6}\right.$ and $30 \mathrm{ml}$ deionized water) was added drop by drop under magnetic stirring then the vacuum cut off and the sample left under mixing for about $2 \mathrm{hr}$ to have a homogenous distribution of metal precursors. The product was slurry filter washed with distilled water, dried at $110^{\circ} \mathrm{C}$ overnight and calcined at $400^{\circ} \mathrm{C}$ for two hours at a rate of $2^{\circ} \mathrm{C} / \mathrm{min}$ [11]. After calcination the catalyst was reduced by hydrogen at $350^{\circ} \mathrm{C}$ for 3 hours. For preoare Ni-Pt/HMOR catalyst containing 0.215 wt. $\%$ of Ni, $50 \mathrm{~g}$ of Pt/HMOR was impregnated with $0.2 \mathrm{M} \mathrm{Ni}\left(\mathrm{NO}_{3}\right)_{2} \cdot 2 \mathrm{H}_{2} \mathrm{O}$ aqueous solution at $40{ }^{0} \mathrm{C}$ for 2 hours. The obtained filtrated, dried and calcined at $400{ }^{\circ} \mathrm{C}$ for 2 hours.

\subsection{Catalytic Activity Test}

The catalytic activity test was achieved in a continuous flow at fixed-bed reactor. Figure 1 shows the process flow diagram of unit. $30 \mathrm{~g} \mathrm{Ni-Pt/H-MOR} \mathrm{was} \mathrm{charged} \mathrm{to} \mathrm{the}$ reactor between two layers of inert ceramic particles. The platinum containing catalyst was reduced with $\mathrm{H}_{2}$ at $350^{\circ} \mathrm{C}$ for $3 \mathrm{hr}$.

The catalytic reaction was carried out with LHSV of 1 $\mathrm{hr}^{-1}$, at temperature range of $220-300^{\circ} \mathrm{C}$, hydrogen to feed mole ratio of 3.7 and at atmospheric pressure.

The reactor was flushed with nitrogen to purge the air from the system. 
Meanwhile, the reactor is heated to the desired temperature. After reaching the reaction temperature, the nitrogen valve was closed.

A pre-specified flow rate of light naphtha was set on. Vaporization of the feed occurs in the evaporator.

The vapor of light naphtha was mixed with specified flow rate of hydrogen in the mixing section. The mixture entered the reactor from the top, and reacted on the surface of catalyst. The final condensed product was collected only after steady state operation was established while initial products were discarded.

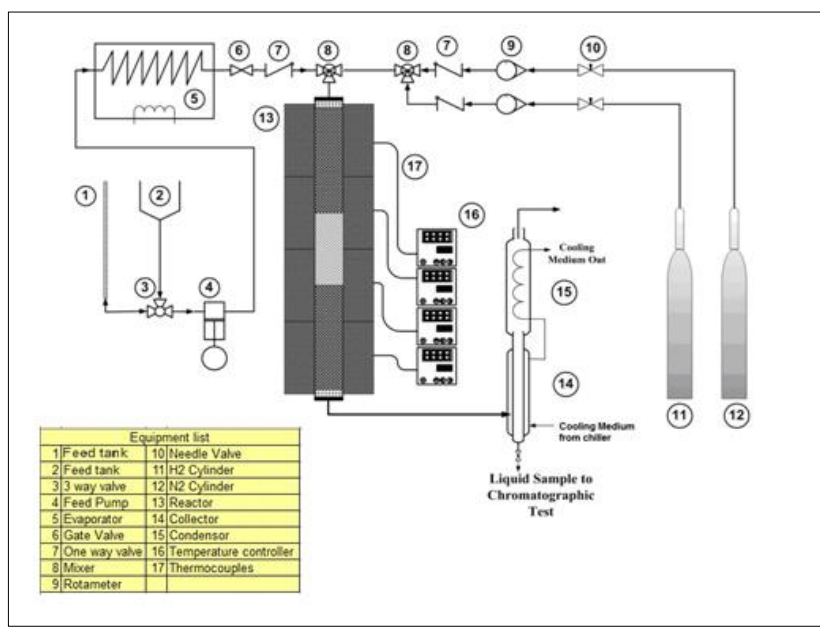

Fig. 1. Process flow diagram of the catalytic experimental unit

\section{3- Results and Discussion}

\subsection{Characterization of Na-MOR and H-MOR.}

\section{a. XRD Analysis}

Fig. 2 shows that the X-ray diffraction patterns of synthesized Na-MOR. These crystal was similar to that obtained by R. Szostak [12] and M. Mohamed et al, [13]. This means that the synthesized sample is Na-MOR crystals.

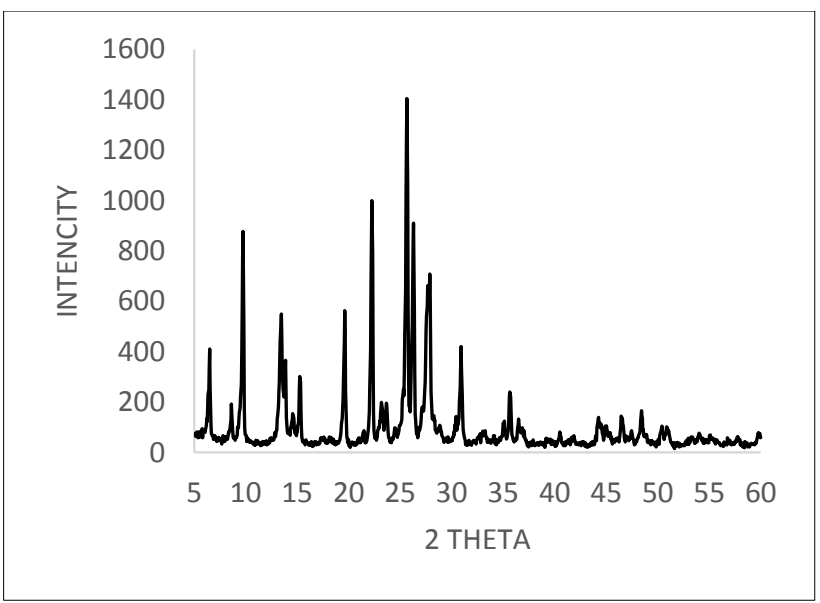

Fig. 2. X-ray powder pattern of prepared Na-MOR zeolite
The exchange technique was used in this work is one step impregnation under a constant temperature to convert Na-MOR zeolite to H-MOR zeolite. Fig. 3, illustrates the XRD patterns of the synthesized zeolite H-MOR. XRD phase is found to match with the show peaks at $2 \theta=6.57$, 9.77, 19.65, 22.36, 25.72 and 26.36. These peaks are characteristic for H-MOR zeolite. It can be seen from Figure 4, that the synthesized sample showed the formation of H-MOR phase [13]. The relative crystnality of H-MOR was calculated by equation 1 and it was 118 $\%$.

Relative crystnality of zeolite $=S_{x} / S_{y} * 100$

Where:

$S_{x}=$ sum of integral peak intensities for the prepared catalyst.

$S_{y}=$ sum of integral peak intensities for the standard catalyst.

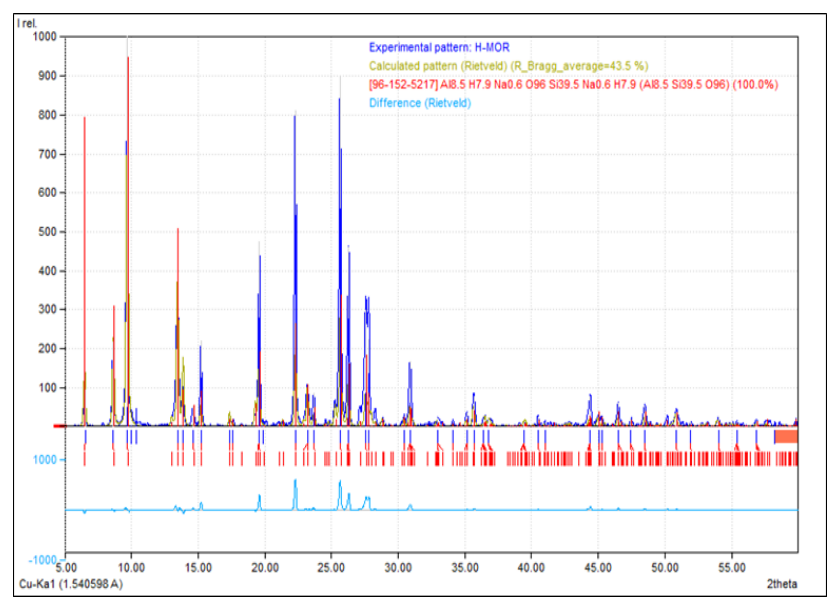

Fig. 3. X-ray powder pattern of prepared H-MOR zeolite

b. Surface Area and Pore Distribution Analysis

$\mathrm{H}-\mathrm{MOR}$ was characterized using $\mathrm{N}_{2}$ sorption to determine their surface area and pore volume. Surface area and pore volume depend mainly on the structure of the solid. It was found that the BET surface area and pore size of H-MOR were $336.7 \mathrm{~m}^{2} / \mathrm{g}$ and $2.49 \mathrm{~nm}$, respectively. The surface area obtained in this work was higher than those obtained by Hisham M. et al, (52.14 $\left.\mathrm{m}^{2} / \mathrm{g}\right)$ [14] and Heman et al, $\left(254.38 \mathrm{~m}^{2} / \mathrm{g}\right)$ [15].

\subsection{Isomerization Conversion}

Isomerization conversion was determined by equation 2 , while percentage decreasing of naphthenic and aromatic calculation by equation 3 .

Isomerization conversion $=\frac{\text { feed }- \text { out }}{\text { feed }} * 100 \%$

Percentage decreases $=\frac{\text { feed-out }}{\text { feed }} * 100 \%$ 
Table 3 shows the chemical composition of produced gasoline using PONA analysis in order to evaluate the catalyst performance. The hydroconversion involves three main reactions hydroisomerization, dealkylation and hydrogenation.

Table 3. PONA analysis for isomerization of Iraqi light naphtha at LHSV $=1 \mathrm{hr}^{-1}$ and different T

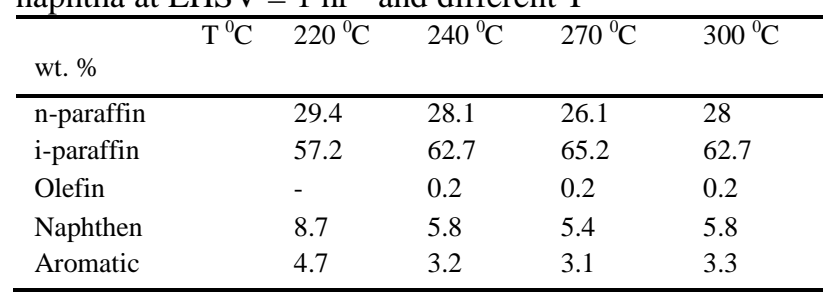

Fig. 4 shows the effect of temperature on the isomerization reaction.

The isomerization conversion, as shown in this figure, increases with temperature increasing up to $270{ }^{\circ} \mathrm{C}$. This is due to n-paraffin isomerization. This agrees with an investigation reported by Mohammed et al, [8] and Maha H. [7] obtained for hydroisomerization light naphtha using Pt-Ni/H-mordenite.

Furthermore, the lower reaction temperature increases the percentage of branch alkane at thermodynamic equilibrium as mentioned by Fahim M A et al. [16].

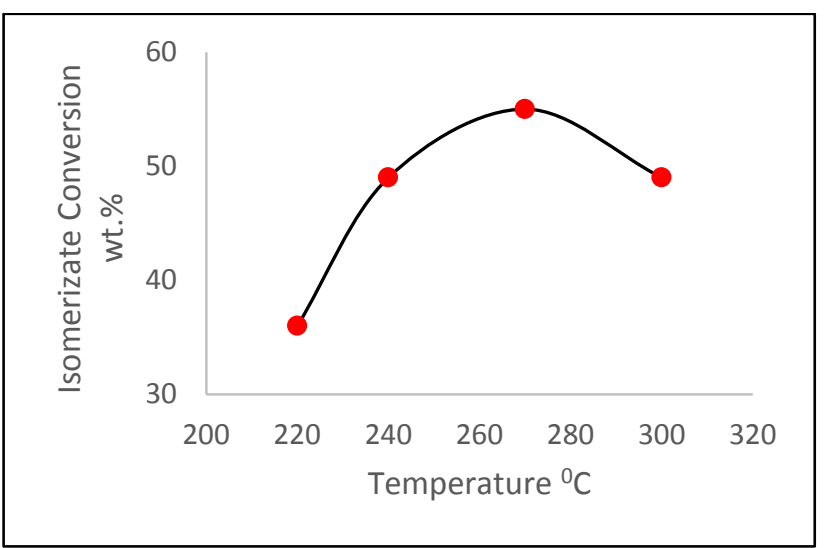

Fig. 4. Effect of temperature on isomerizate conversion of Iraqi light naphtha on $\mathrm{Pt}-\mathrm{Ni} / \mathrm{H}-$ mordenite catalyst at LHSV $=1 \mathrm{hr}^{-1}$

Fig. 5 and Fig. 6 show the relationship between percentage change of naphthene and aromatic with temperature, respectively.

The increasing of temperature firstly, promote aromatic hydrogenation to cyclo-paraffin and cyclo-paraffin hydroisomerization to iso-paraffin and secondly, higher temperature change the thermodynamic equilibrium forward decreasing hydroisomerization as mentioned by Al-Hassany M. [7] at different temperature 220-300 ${ }^{\circ} \mathrm{C}$, constant $\mathrm{LHSV}=1 \mathrm{hr}^{-1}$ and $\mathrm{H}_{2} /$ hydrocarbon mole ratio $=$ 3.7

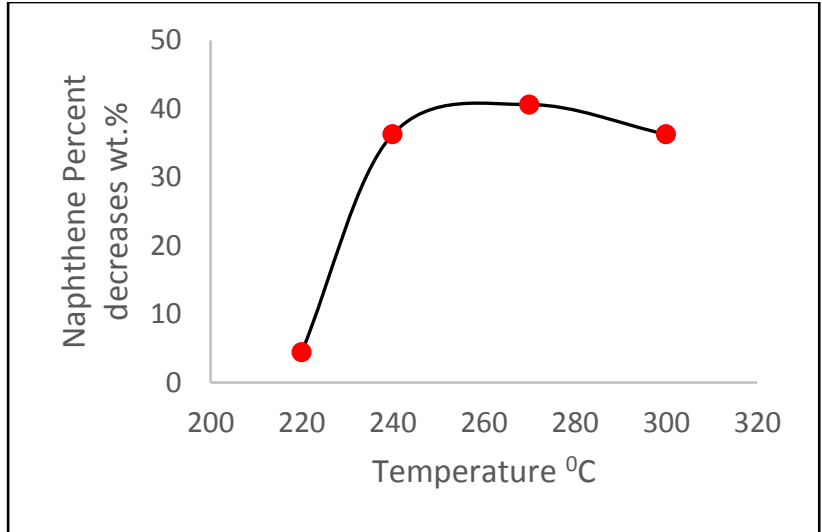

Fig. 5. Effect of temperature on naphthene percent decreas of Iraqi light naphtha on $\mathrm{Pt}-\mathrm{Ni} / \mathrm{H}$-mordenite catalyst at $\mathrm{LHSV}=1 \mathrm{hr}^{-1}$

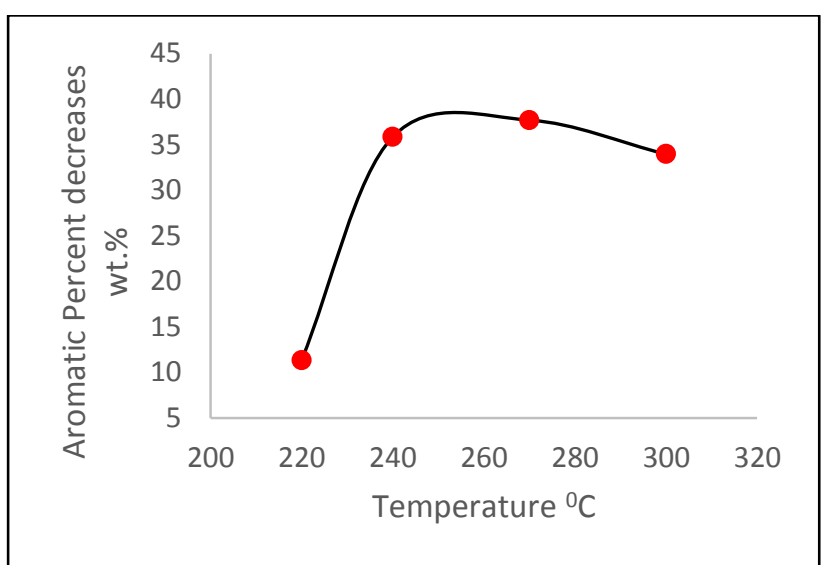

Fig. 6. Effect of temperature on aromatic percent decrease of Iraqi light naphtha on $\mathrm{Pt}-\mathrm{Ni} / \mathrm{H}-$ mordenite catalyst at $\mathrm{LHSV}=1 \mathrm{hr}^{-1}$

Fig. 7 shows the octane number of produced light naphtha at different temperature. This figure shows that the octane number of produced light naphtha (isomerization) more higher than the light naphtha (RON =60) and the maximum octane number (92) obtained at $270{ }^{\circ} \mathrm{C}$. The isomeizate obtained at $270{ }^{\circ} \mathrm{C}$ can be easy used as high octane component for producer lead free automobile gasoline.

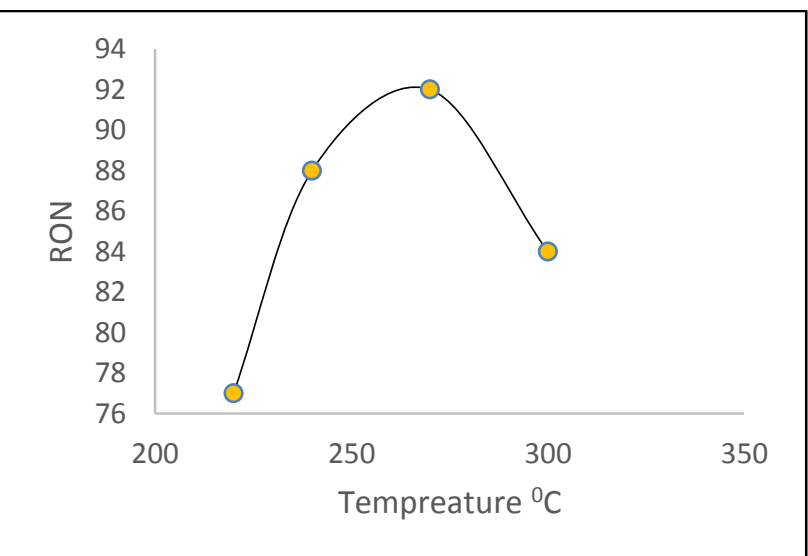

Fig. 7. The highr of temperature on the RON at LHSV 1 $\mathrm{hr}^{-1}$ 


\section{4- Conclusions}

The prepared catalyst Ni-Pt/H-mordenite exhibits a high hydroisomerization activity within the studied range of operating conditions. The hydroisomerization reaction is temperature dependent, and the lower temperature the greater hydrosiomerization selectivity and in turn high RON value. The isomerizate at $270{ }^{\circ} \mathrm{C}$ and LHSV $=1 \mathrm{hr}^{-1}$ has $\mathrm{RON}=92$ and can be used as component for lead free gasoline production.

\section{References}

[1] Pope, Tim D., et al. "A study of catalyst formulations for isomerization of C7 hydrocarbons." Applied Catalysis A: General 233.1-2 (2002): 45-62.

[2] Pham-Huu, Cuong, et al. "n-Hexane and n-heptane isomerization at atmospheric and medium pressure on MoO3-carbon-modified supported on $\mathrm{SiC}$ and $\gamma$ Al2O3." Applied Catalysis A: General 132.1 (1995): 77-96.

[3] Sabyrov, Kairat, et al. "Hydroisomerization of nhexadecane: remarkable selectivity of mesoporous silica post-synthetically modified with aluminum." Catalysis $\quad$ Science \& Technology 7.8 (2017): 1756-1765.

[4] Exner, H., E. Nagy, and F. Fetting. "Kinetics of the hydroisomerization of n-hexane on nickel containing zeolites." Preprints-American Chemical Society. Division of Petroleum Chemistry 36.4 (1991): 853863.

[5] Song, Xuemei, et al. "The effect of palladium loading on the catalytic performance of Pd/SAPO-11 for $\mathrm{n}$ decane hydroisomerization." Molecular Catalysis 433 (2017): 84-90.

[6] Vaudagna, S. R., R. A. Comelli, and N. S. Figoli. "Influence of the tungsten oxide precursor on WOxZrO2 and Pt/WOxZrO2 properties." Applied Catalysis A: General 164.1-2 (1997): 265-280.

[7] Al-Hassany, Maha. "Effect of $\mathrm{ZrO} 2$, WO3 additives on catalytic performance of $\mathrm{Pt} / \mathrm{HY}$ zeolite compared with $\mathrm{Pt} / \gamma-\mathrm{Al} 2 \mathrm{O} 3$ for Iraqi Naphtha transformation." Journal of Engineering 15.4 (2009): 4378-4392.

[8] Al-Saraj, Mohammed Abd Atiya, Ameel Mohammed Rahman, and Maha H. Al-Hassani. "Enhancement of Iraqi light naphtha octane number using Pt Supported HMOR zeolite catalyst." Al-Khwarizmi Engineering Journal 9.4 (2013): 1-11.

[9] Hussain, H. M., and A. A. K. Mohammed. "Preparation and Characterization of mordenite Zeolite from Iraqi Sand." IOP Conference Series: Materials Science and Engineering. Vol. 518. No. 6. IOP Publishing, 2019.
[10] Ahmedzeki Nada S., Selahattin Yilmaz, and Ban A. Al-Tabbakh. "Synthesis and Characterization of nanocrystalline zeolite Y." Al-Khwarizmi Engineering Journal 12, no. 1 (2016): 79-89.

[11] Güleç, Hilal. Liquid phase hydrogenation of citral on zeolite supported monometallic (Ni, Pt) and bimetallic (ni-Sn, Pt-Sn) catalysts. MS thesis. Izmir Institute of Technology, 2005.

[12] Szostak, R. "Molecular Sieves, Principles of Synthesis and Identification. 1989." New York: Thomson Science (1989).

[13] Mohamed, Mohamed M., Ahmed KH Nohman, and Mohamed I. Zaki. "Development of catalytic properties of mordenite zeolite via chemical modification." Catalysis 4 (2005).

[14] Aly, Hisham M., Moustafa E. Moustafa, and Ehab A. Abdelrahman. "Synthesis of mordenite zeolite in absence of organic template." Advanced Powder Technology 23.6 (2012): 757-760.

[15] Smail, H., K. Shareef, and Z. Ramli. "Synthesis of mesoporous mordenite zeolite by different natural raw materials." Aust J Basic App Sci 11 (2017): 27-34.

[16] Fahim, Mohamed A., Taher A. Al-Sahhaf, and Amal Elkilani. Fundamentals of petroleum refining. Elsevier, 2009. 


\title{
Ni-Pt / H-Mordenite دراسة علية لأيزوميتة النفتا العراقية الخفيفة على
}

\author{
هالة محمد حسين و عبدالحليم عبدالكريم محمد
}

كلبة الفارابي الجامعة-بغداد-العراق

الخلاصة

تمت دراسة عملية الازمرة من النفتا العراقية على محفزالحضر Ni-Pt / H-mordenite عند درجة حرارة

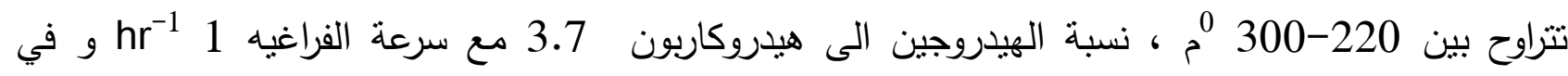
الضغط الجوي.

أظهرت النتائج ان تحول النفتا يزداد مع زيادة درجة حرارة التفاعل عند ثبوت السرعه ، في حين أن تكوين

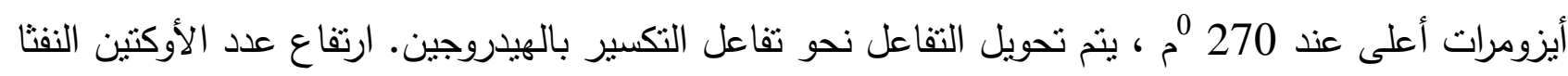
المتكون عند اليزومرات اعلى عند 270 م. الكلمات الدالة: أزمرة النفتا العراقية الخفيفه, نيكل-بلاتثنيوم على موردنايت. 